\title{
Effect of Humidity on Thermal Comfort in the Humid Tropics
}

\author{
Harimi Djamila*, Chi-Ming Chu, Sivakumar Kumaresan \\ School of Engineering and Information Technology, Universiti Malaysia Sabah, Kota Kinabalu, Malaysia \\ Email: ${ }^{\text {harimi1@yahoo.fr }}$
}

Received 20 March 2014; revised 27 April 2014; accepted 7 May 2014

Copyright (C) 2014 by authors and Scientific Research Publishing Inc.

This work is licensed under the Creative Commons Attribution International License (CC BY).

http://creativecommons.org/licenses/by/4.0/

c) (i) Open Access

\begin{abstract}
This paper presents the main findings of the effect of indoor humidity on occupants' thermal comfort in the humid tropics of Malaysia. An extensive field investigation was carried out in Kota Kinabalu city and the surrounding areas, located in East Malaysia. A total of 890 individuals were asked to complete a questionnaire. Measured indoor climates were also recorded. The survey was designed as cross sectional data collection. The present investigation found that the occupants were thermally comfortable at wide relative humidity range. The mean relative humidity corresponding to the optimum comfort temperature was close to $73 \%$. Regression models failed to predict accurately the effect of relative humidity on occupants' thermal perceptions. In addition, a quadratic regression model was developed for the prediction of the mean indoor relative humidity based on indoor temperature. The suggested regression model can be used for an approximate prediction of indoor relative humidity when required.
\end{abstract}

\section{Keywords}

Humidity, Thermal Comfort, Malaysia, Humid-Tropics

\section{Introduction}

This humidity is among the indoor environmental factors that could affect thermal comfort in a building. Researches on thermal comfort at higher humidity levels were mostly carried out in climate chamber or air-conditioned spaces. Little observational studies were concerned with the direct effect of humidity on thermal comfort. This might be attributed partly to the major concern on validating the PMV in air conditioned spaces and the adaptive model in naturally conditioned spaces. However, currently, the return backs to investigating the environmental factors such as air movement, humidity and indoor air quality seems to capture research interests.

\footnotetext{
"Corresponding author.
} 
It is widely accepted, that evaporative cooling is among the preferred method to improve the indoor thermal comfort during summer dry seasons. Conversely, air movement is the preferred strategy for enhancing the indoor thermal perception in the humid tropics. The evaporative heat loss due to regulatory sweating is the major heat loss from the human body. Thereby; at higher humidity and lower air movement, thermal comfort may not be achieved. Why this was not reported in field studies carried out in the humid tropics? This is not known yet. Are people in the humid tropics satisfied with the high humidity levels?

Despite the fact that thermal comfort might be occasionally achieved at very high indoor air temperatures and humidity levels under hot-dry climatic conditions. It is not yet known how an acclimatized person subjected to the higher humidity levels will perceive the indoor thermal environment. This study has the main objective to investigate the humidity effect on thermal comfort in naturally ventilated buildings in the humid tropics of Malaysia.

\section{Humidity and Thermal Comfort Standards}

Thermal comfort is a state of mind which describes the satisfaction toward the indoor thermal environment [1] [2]. Air dry bulb temperature, mean radiant temperature, air velocity and humidity are the most known environmental parameters in field thermal comfort studies. Humidity refers to the mass of water vapor in a unit volume of air (moisture content). It can be expressed in several variables such as vapor pressure, dew point temperature, humidity ratio, and relative humidity. It is widely accepted that higher humidity and air temperature intensifies thermal sensation and reduces perspiration and evaporation of the body's capacity, consequently the body cannot be cooled by evaporation [3]. However, this was not observed in air-conditioned spaces. The following statement is quoted from Arens et al. [4].

Although there are no upper and lower limits to humidity from a thermal comfort standpoint. Limits are suggested for the still air comfort zone based on the following practical considerations vapor pressures above 1.86 $\mathrm{kPa}(14 \mathrm{~mm} \mathrm{Hg})$ will cause moisture arid mold problems indoors, and vapor pressures below $0.67 \mathrm{kPa}(5 \mathrm{~mm}$ $\mathrm{Hg}$ ) are likely to cause respiratory discomfort.

According to Olesen and Parsons, the recommended humidity level was behind several discussions in revision of standards [5]. The history of ASHRAE with thermal comfort might be traced back to 1967 [6]. Subsequent revisions of the ASHRAE Standards with the maximum allowed humidity levels are well described in the literature review accomplished by some investigators [6] [7] and updated during this study. ASHRAE 55-1981 [8] specified the comfort range according to the humidity ratio $(\mathrm{g} / \mathrm{kg})$. This was kept in most of the subsequent ASHRAE standards.

ASHRAE 55-1992 [9] set the maximum air relative humidity at 60\%. This is because mold and mildew start to grow beyond this limit. ASHRAE 55-1994 [10] tolerated slightly higher relative humidity to include evaporative air conditioning; whereas no lower humidity level was recommended in ASHRAE 55-2004 [11]. This is because the humidity for thermal comfort is negligible. However, it might have secondary health implications as stated by the same standard. For instance, at low relative humidity, the increase in evaporation rate may cause skin drying and irritation [12]. An upper humidity ratio of 0.012 was set by the ASHRAE 55-2004 [11]. The upper humidity ratio was postulated for systems designed to control humidity. This corresponds to an upper relative air humidity level of about $80 \%$ at a low dry bulb temperature of about $20^{\circ} \mathrm{C}$.

ASHRAE 55-2010 [1] kept the limit of the humidity ratio to 0.012. Again the standard does not specify a minimum humidity level. However, the standard clearly states that other factors may place limits on the minimum humidity level, such dryness of the skin and eyes and others. Additionally, the standard did not set limits for humidity or air speed when the adaptive model chart is used. Interestingly, all comfort charts of ASHRAE 55 since 1981 [8] were slopped vertically from lower right to upper left. This reflects that the effect of humidity on thermal become more significant when operative temperatures are above $27^{\circ} \mathrm{C}$. Whereas at lower operative temperatures below $21^{\circ} \mathrm{C}$, the relative humidity seems to improve thermal comfort (eg. in ASHRAE chart 2010) [1]. It is necessary to emphasize that those charts might be more appropriate for air-conditioned spaces. This may not be the case for naturally ventilated buildings.

From the reviews above, it appears that the humidity effect on thermal comfort in air-conditioned spaces might not be the most determinant factor. This is due to the strict limitations of humidity imposed for health, indoor air quality, and other factors [5] [13] [14]. The present study provides further insight on the effect of humidity on occupants' thermal comfort in naturally conditioned buildings subjected to elevated humid level all 
year round.

\section{Materials and Methods}

A field study took place in Kota Kinabalu city located on the coastline of Sabah state at 5056'N Latitude, 116003' Longitude in a tropical hot-humid environment. The survey was carried out in forty two building locations. Most of the visited locations are red spotted in Figure 1. The surveyed buildings have a spectrum of architectural features, styles, and building materials. Typical houses in Kota Kinaabalu are shown in Appendix A1. The objective of the experimental design was that the field survey should be conducted under various indoor climate conditions and spans over a period of at least one full year. The field survey was designed in such a way to ensure monthly and hourly daytime records. This is to provide an accurate and more representative evaluation of the population under investigations. Kota Kinabalu city was considered the center of the visited buildings. All the surrounded locations within the center were also the selected study area. Table 1 provides a summary of the surveyed buildings. Each subject and each house have been visited once.

The number of the surveyed subjects was 949 records. Records were reduced to 890 when filtered against the criteria established before analysis. Only acclimatized subjects for no less than one year were included in the final analysis. The survey was designed as cross sectional data collection.

The highest percentages of the surveyed occupants were under the category "Normal Weight". The average clothing insulation level worn by the subjects was about 0.3 clo. The estimated average surface area for a typical Malaysian body proportion was $1.62 \mathrm{~m}^{2}$. The metabolic rate of the surveyed subjects was in the range of 0.94 and 1.30 met.

The age of the occupant was set to be no less than 15 years old. Other requirements set in the present survey were that the occupant should be free from any major health problem, should not have a fever, flu or any disease that may have an effect on the prediction of the neutral temperature. Further information about data collection and preliminary data analysis is well documented in our previous publication [15].

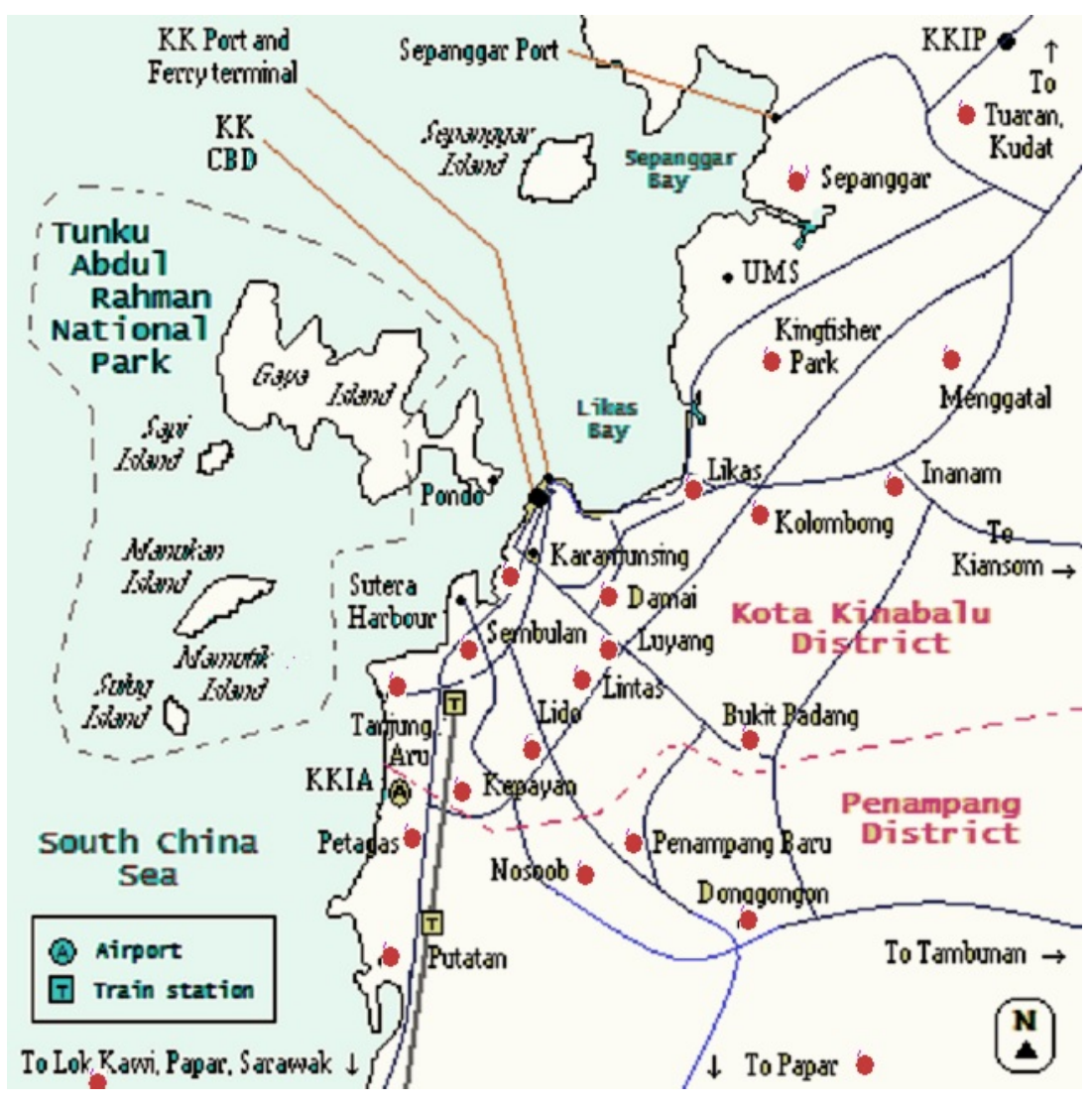

Figure 1. Sites location of the surveyed buildings. 
Table 1. Summary of the surveyed buildings.

\begin{tabular}{ccccc}
\hline \multicolumn{2}{c}{ Type of Building } & \multicolumn{3}{c}{ Number of Respondents } \\
Terrace & & & 323 \\
Semi Detached and Detached & Not Urban & & 192 \\
Houses & Urban & 71 & 375 & 890 \\
Apartment - Flat & & & & \\
Total & & & & \\
\hline
\end{tabular}

Note: H.W.: Heavy weight building material such as concrete or brick; L.W.: Light weight building material mostly wooden houses.

\section{Results and Discussion}

The relationship between indoor air temperature as the independent variable and relative humidity as the dependent variable was first examined. This is by calculating linear, quadratic, cubic and others available models in the SPSS 17. Figure 2 shows a scatter plot of the indoor air temperature vs. indoor relative humidity for further illustration.

The relationship between indoor air temperature $\left(T_{a}\right)$ and relative humidity $\left(R H_{(K K-\mathrm{in})}\right)$ during field study was best described with a quadratic model $\left(\mathrm{n}=890, \mathrm{r}=0.692, \mathrm{r}^{2}=0.479\right.$. Adjusted $\mathrm{r}^{2}=0.478, \mathrm{~F}=407.382, P$ Value $=0.000)$.

$$
R H_{(k k-\mathrm{in})}=0.202 T_{a}^{2}-15.365 T_{a}+352.293
$$

To investigate the relationship between mean indoor air temperature in the bin $\left(T_{a(\text { mean })}\right)$ and mean relative humidity per temperature bin $\left(1^{\circ} \mathrm{C}\right)\left(R H_{(\text {mean })}\right)$, quadratic regression also was chosen to find the equation of this line. The variables of the equation and the standard deviation of the estimated mean relative humidity values are presented in Table 2.

The plotted values with their corresponding confidence and predicted intervals are shown in Figure 3.

The coefficient of the determination of the quadratic regression was close to one corresponding to a perfect quadratic relationship between the two variables. $\left(r^{2}=0.993\right.$, Adjusted $r^{2}=0.991, F=430.907, P$ value $=0.000$, $\mathrm{n}=9$ ). The regressed model is expressed by Equation (2)

$$
R H_{(\text {mean }-K K-\text { in })}=0.140 T_{a(\text { mean })}^{2}-11.679 T_{a(\text { mean })}+297.188
$$

Both methods provided almost similar outcomes. Shanmugavelu [16] also developed a non-linear regression from fifteen thousand paired outdoor temperatures and relative humidity dataset supplied by the Kuala Lumpur meteorological office [16]. The resulting model for Shanmugavelu investigation was:

$$
R H_{(\text {out }-K L)}=0.0598 T_{a}^{2}-7.106 T_{a}+231.04
$$

The present investigation provided a possibility for comparison of results between the two models within the range of the field survey associated with the indoor air temperature. This is shown in Figure 4.

A glance at the multiple bar graph revealed that the maximum difference in the relative humidity between the two studies is no more than $4 \%$ when using mean values. The highest discrepancy of $6 \%$ was noted when considering all responses. Overall, the current model is consistent with the Shanmugavelu prediction within the indoor temperature range of $27^{\circ} \mathrm{C}$ to $35^{\circ} \mathrm{C}$. Therefore the results might be used for an approximate prediction of indoor relative humidity from indoor air temperature when needed. In essence, the generated quadratic regression (Equation (2)) appears to be more precise for the prediction of the mean relative humidity values. This is due to the high variability of the recorded relative humidity reflected by the wide predicted interval and the variability of the standard deviation at each mean temperature bin.

Figure 4 shows that relative humidity is steadily decreasing over air temperature, suggesting the existence of collinearity between the two variables. This was further confirmed from the developed Equations (1) and (2). It is necessary to report that the comfort temperature was predicted from indoor air temperature in our previous investigation [15] [17]. From the analysed results, it can be said that the isolation of the individual contribution of relative humidity and air temperature to an occupant thermal sensation vote of seven-point ASHRAE scale is not possible. The high correlation coefficient between mean air temperature and mean relative humidity suggests 


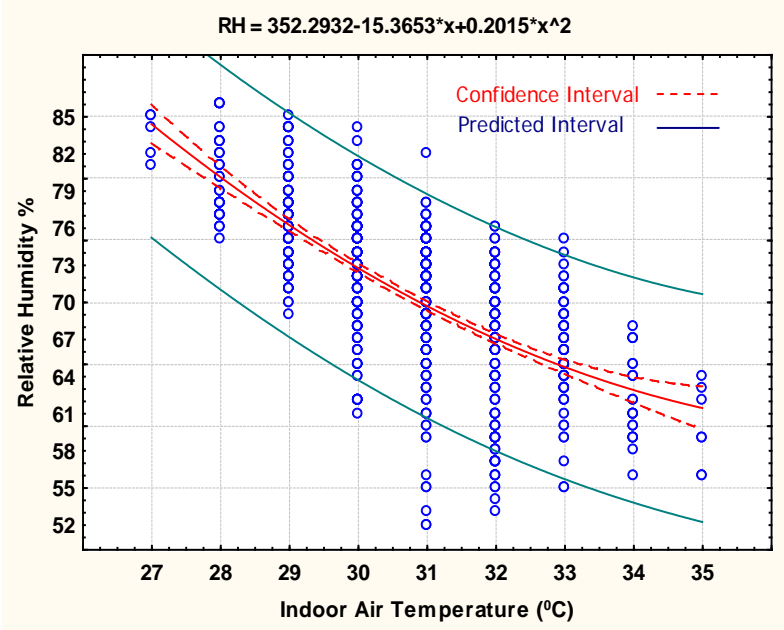

Figure 2. Indoor air temperature versus relative humidity with the corresponding confidence and predicted interval.

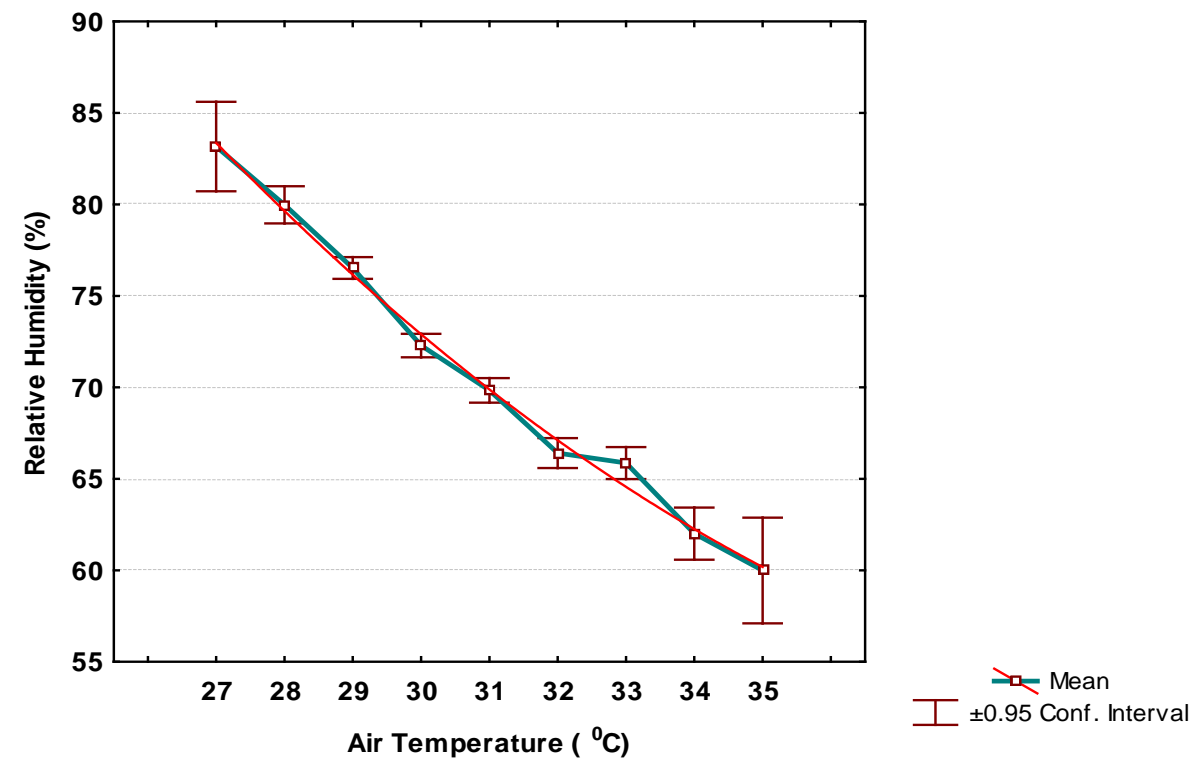

Figure 3. Mean air temperature in the bin vs. mean relative humidity per temperature bin.

Table 2. Variation of mean relative humidity with indoor air temperature.

\begin{tabular}{ccc}
\hline Air Temperature $\left({ }^{\circ} \mathbf{C}\right)$ & Mean Relative Humidity \% & Standard Deviation \\
\hline 27.1 & 83.16 & 1.97 \\
28.2 & 79.97 & 3.29 \\
29.0 & 76.52 & 3.55 \\
30.0 & 72.28 & 4.59 \\
30.9 & 69.83 & 5.04 \\
31.9 & 66.40 & 5.47 \\
32.9 & 65.86 & 3.93 \\
33.9 & 62.00 & 3.29 \\
34.9 & 59.99 & 3.12 \\
\hline
\end{tabular}




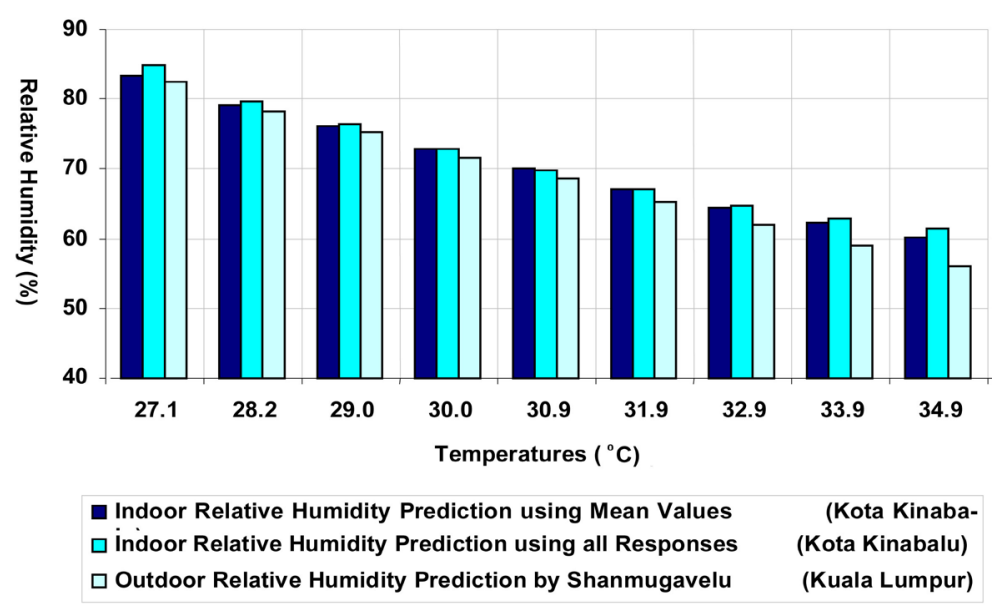

Figure 4. Comparison between relative humidity in the present study and in Shanmugavelu investigation.

that statistically the combination of these two parameters for the use of multiple regression analysis for indoor thermal comfort prediction may not be valid.

For further analysis of the effect of relative humidity on occupants' thermal comfort, the comfort temperature was predicted for seven-point ASHRAE scale. The reader may refer to our previous study [17] for more information about the predicted comfort temperature. Therefore, it will not repeat it here. The estimated comfort temperature value was about $\left(30^{\circ} \mathrm{C}\right)$. The acceptable comfort zone corresponding to the optimum percentages of votes within the central three categories $(-1,0,1)$ on the ASHRAE thermal sensation scale varied from $27.5^{\circ} \mathrm{C}$ to $33.5^{\circ} \mathrm{C}$. The estimated comfort band is $6^{\circ} \mathrm{C}$ [17]. Further investigation showed that the determination of the mean relative humidity at the optimum neutral temperature is feasible. This can be done by substituting the neutral (comfort) temperature into Equation 1 or Equation (2). The mean relative humidity corresponding to a neutral temperature of $30^{\circ} \mathrm{C}$ is about $73 \%$. For the indoor thermal comfort range of $27.5^{\circ} \mathrm{C}$ and $33.5^{\circ} \mathrm{C}$ [15], the corresponding mean relative humidity values were within the range of $82 \%$ and $63 \%$ respectively. This is when applying Equation (2). This shows occupants tolerance to higher humidity levels. Thus, humidity may not affect occupant thermal comfort.

Tanabe et al. [18] [19] also did not observe in their thermal comfort studies any increase in thermal sensation due to higher air relative humidity. Fountain et al. [7] found few differences in human response to air relative humidity exposure between $60 \%$ and $90 \%$ of the temperature range $20^{\circ} \mathrm{C}-26^{\circ} \mathrm{C}$ (new effective temperature) while sedentary. They highlighted that they were not able to distinguish the impact of air humidity on human response in their data. The authors presumed that the few differences could be a result of the increased skin temperature and sweating. McIntyre [20] reported that the difference in air relative humidity as $20 \%$ and $70 \%$ can be undetectable within the comfort zone. ISO 7730-2005 [2] stated in the informative part of the standard (Informative is not a formal part of the standard); that in moderate environment the rise of $10 \%$ in relative humidity is comparable to an increase in operative temperature by $0.3^{\circ} \mathrm{C}$. According to the standard, this has a modest impact on thermal sensation, but the situation might be different for higher activity levels. Even though the reason behind the selection of $0.3^{\circ} \mathrm{C}$ in the standard is not known, the same observation was noted earlier by Nevins et al. [21] in the tested temperature range of $18.9^{\circ} \mathrm{C}$ and $27.8^{\circ} \mathrm{C}$.

Bauman et al. [22] observed that the humidity affects occupant thermal sensation under increased metabolic rate. This was in agreement with an earlier study carried out by McNall et al. [23]. However, the authors did not register any considerable effect of higher air relative humidity within temperature range of $15.6^{\circ} \mathrm{C}$ and $40.6^{\circ} \mathrm{C}$ and air relative humidity of $20 \%$ and $90 \%$. It may be interesting to mention that the recommended design air relative humidity in the Malaysian Standard for non-residential buildings were $60 \%$ to $70 \%$, with the minimum acceptable relative humidity level of 55\% [24]. The maximum relative humidity recommended by building regulations of Singapore in 1986was $75 \%$ of air-conditioned space [25].

\section{Conclusions}

The current analysis and the data from this investigation offered valuable information on people thermal comfort 
toward indoor humidity. The analysis of relative humidity dataset revealed that the suggested quadratic regression models from the present work were in close agreement with the developed model by Shanmugavelu [16]. His model was developed from 15,000 of paired outdoor temperature and relative humidity dataset in Kuala Lumpur [16]. Therefore a regression model was suggested. This may help in estimating relative humidity from air temperature. This is very useful in case of non-availability of hygrometer. It also helps any study which requires approximate prediction of the indoor relative humidity. However, it remains valid within the range under investigation under Malaysian Climate

People Thermal comfort in the humid tropics might not to be affected by the variation of relative humidity. Therefore, higher relative humidity in air-conditioned spaces might be acceptable. In non-air conditioned spaces in the humid tropics of Malaysia, the separation between both air temperature and relative humidity parameters was neither possible nor necessary. This is because; we found that the two parameters are highly correlated. In future field research studies, it is recommended to investigate the direct humidity effects on subjects' thermal perceptions due to sweating, and might be due to the heavy feeling of the saturated air on thermal preference. This is because the subjects in the humid tropics are mostly exposed to higher humidity levels all year round. Research on the effect of higher humidity levels at higher indoor temperatures on the deterioration of indoor quality is highly recommended.

\section{References}

[1] ASHRAE 55 (2010) ASHRAE Standard 55-2010. Thermal Environmental Conditions for Human Occupancy. American Society of Heating, Refrigerating and Air-Conditioning Engineers, Atlanta.

[2] ISO 7730 (2005) Ergonomics of the Thermal Environment-Analytical Determination and Interpretation of Thermal Comfort Using Calculation of the PMV and PPD indices and Local Thermal Comfort Criteria: International Organization for Standardization.

[3] Holm, D. and Engelbrecht, F.A. (2005) Practical Choice of Thermal Comfort Scale and Range in Naturally Ventilated Buildings in South Africa. Journal of the South African Institution of Civil Engineering, 47, 9-14.

[4] Arens, E., Gonzalez, R. and Berglund, L. (1986) Thermal Comfort under an Extended Range of Environmental Conditions. ASHRAE Transactions, 92, 18-26.

[5] Olesen, B.W. and Parsons, K.C. (2002) Introduction to Thermal Comfort Standards and to the Proposed New Version of EN ISO 7730. Energy and Buildings, 34, 537-548. http://dx.doi.org/10.1016/S0378-7788(02)00004-X

[6] Sreshthaputra, A. (2003) Building Design and Operation for Improving Thermal Comfort in Naturally Ventilated Building in a Hot-Humid Climate. Ph.D. Thesis in Architecture, Texas A \& M University.

[7] Fountain, M., Arens, E., Xu, T., Bouman, F. and Massayuki, O. (1999) An Investigation of Thermal Comfort at High Humidifies. ASHRAE Transactions, 105, 1-10.

[8] ASHRAE 55 (1981) Thermal Environmental Conditions for Human Occupancy. American Society of Heating, Refrigerating and Air-Conditioning Engineers, Atlanta.

[9] ASHRAE 55 (1992) Thermal Environmental Conditions for Human Occupancy. American Society of Heating, Refrigerating and Air-Conditioning Engineers, Atlanta.

[10] ASHRAE 55 (1994) Thermal Environmental Conditions for Human Occupancy. American Society of Heating, Refrigerating and Air-Conditioning Engineers, Atlanta.

[11] ASHRAE 55 (2004) ASHRAE Standard 55-2004. Thermal Environmental Conditions for Human Occupancy. American Society of Heating, Refrigerating and Air-Conditioning Engineers, Atlanta.

[12] Ibrahim, H. and Hazrin, A.R. (2009) Field Study on Thermal Comfort in Malaysia. European Journal of Scientific Research, 37, 134-152.

[13] Berglund, L.G. (1998) Comfort and Humidity. ASHRAE Transactions, 40, 35-41.

[14] Fang, L., Glausen, G. and Fanger, P.O. (1996) The Impact of Temperature and Humidity on Perception and Emission of Indoor Air Pollutants. Proceedings of Indoor Air'96, 21-26 July 1996, Institute of Public Health, Tokyo, 349-354.

[15] Djamila, H., Chu, C.M. and Kumaresan, S. (2013) Field Study for Prediction and Evaluation of Comfort in Residential Buildings in the Equatorial Hot-Humid Climate of Malaysia. Building and Environment, 62, 133-142. http://dx.doi.org/10.1016/j.buildenv.2013.01.017

[16] Davis, M.P., Ghazali, M. and Nordin, N.A. (2006) Thermal Comfort Honeycomb Housing. Dar Ehsan, Selangor.

[17] Djamila, H. (2012) Neutral Temperature for Naturally Ventilated Residences in Kota Kinabalu, Sabah, Malaysia. Ph.D. Thesis, School of Engineering and Information Technology, Universiti Malaysia Sabah, Kota Kinabalu. 
[18] Tanabe, S., Kimura, K. and Hara, T. (1987) Thermal Comfort Requirements during the Summer Season in Japan. ASHRAE Transactions, 93, 564-577.

[19] Tanabe, S. and Kimura, K. (1994) Effect of Air Temperature, Humidity, and Air Movement on Thermal Comfort under Hot and Humid Conditions. ASHRAE Transactions, 100, 953-969.

[20] McIntyre, D.A. (1980) Indoor Climate. Applied Science Publishers LTD, London.

[21] Nevins, R., Rohles, F., Springer, W. and Feyerherm, A. (1966) Temperature-Humidity Chart for Thermal Comfort of Seated Persons. ASHRAE Transactions, 72, 283-291.

[22] Bauman, F.S., Arens, E., Huizenga, C., Xu, T., Zhang, H., Akimoto, T. and Miura, K. (1996) The Impact of Humidity Standards on Energy Efficient Cooling in California. Final Report ASHRAE RP-781. California Institute for Energy Efficiency: Center for Environmental Design Research, Berkeley.

[23] McNall, P.E., Jaax, F.H. Rohles, Nevins, R.G. and Springer, W.E. (1967) Thermal Comfort (Thermally Neutral) Conditions for Three Levels of Activity. ASHRAE Transactions, 73, 1-14.

[24] MS (Malaysian Standard) 1525 (2001) Code of Practice for Energy Efficiency and Use of Renewable Energy for Nonresidential Buildings: Department of Standards Malaysia.

[25] P.W.D (The Development and Building Control Division) (1986) Handbook on Energy Conservation in Buildings and Building Services. Building and Construction Authority, the Development and Building Control Division, Singapore. 
Appendix 1

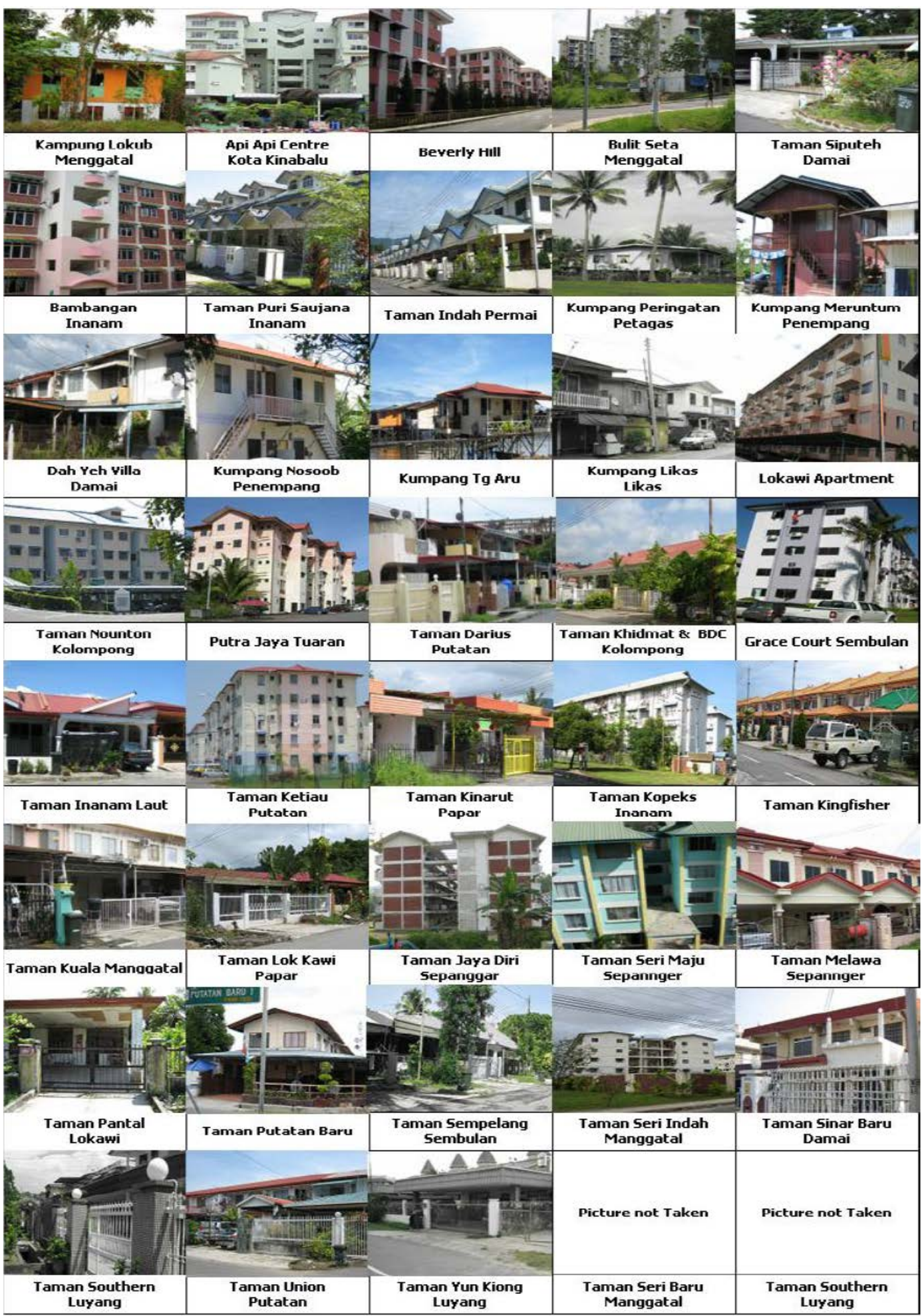

Figure A1. Typical houses in Kota Kinabalu, Malaysia. 
Scientific Research Publishing (SCIRP) is one of the largest Open Access journal publishers. It is currently publishing more than 200 open access, online, peer-reviewed journals covering a wide range of academic disciplines. SCIRP serves the worldwide academic communities and contributes to the progress and application of science with its publication.

Other selected journals from SCIRP are listed as below. Submit your manuscript to us via either submit@scirp.org or Online Submission Portal.
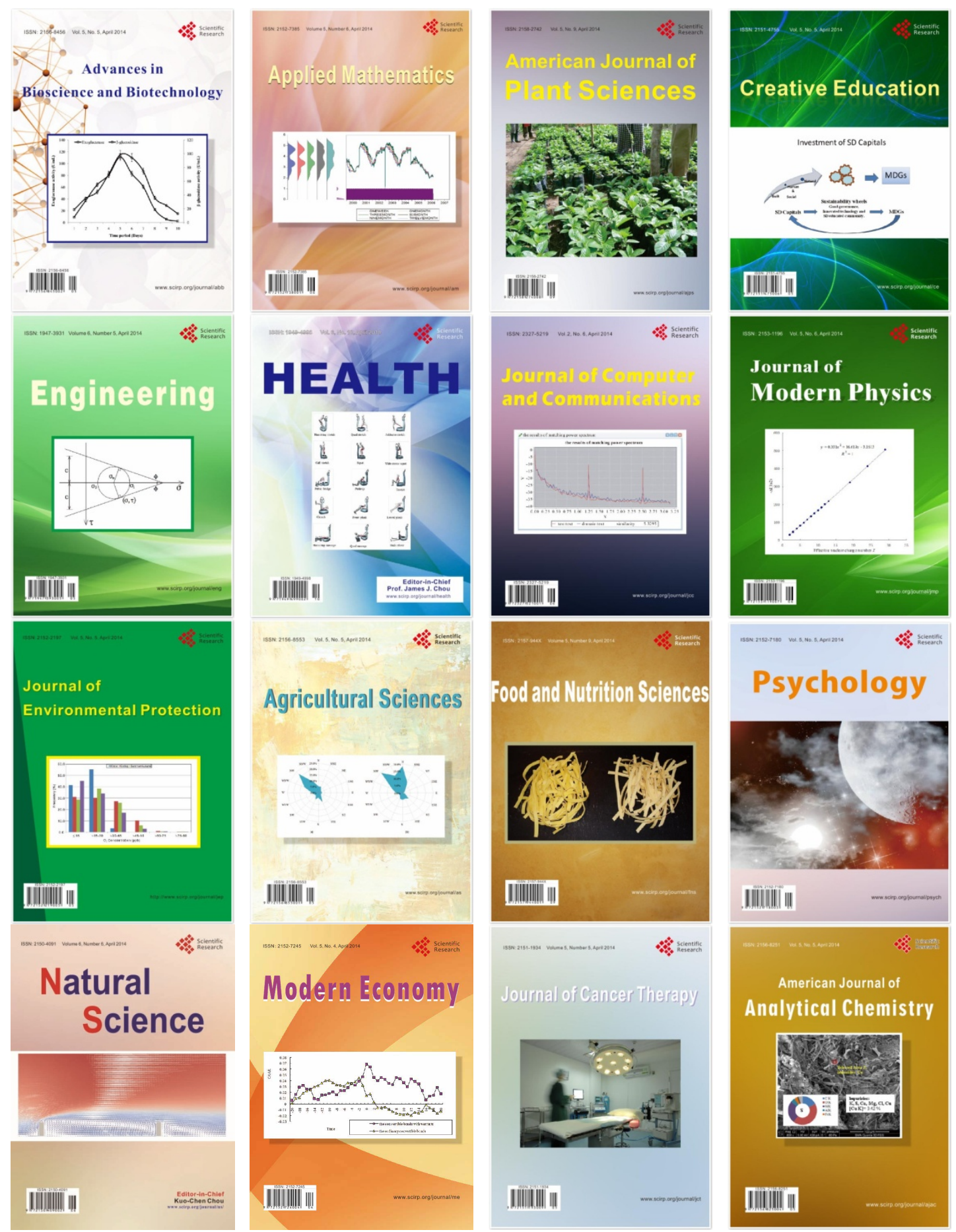